\title{
Serum calprotectin as a novel biomarker for severity of COVID-19 disease
}

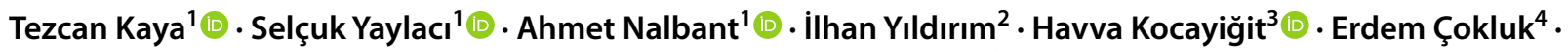 \\ Mehmet Ramazan Şekeroğlu ${ }^{4}(1) \cdot$ Mehmet Köroğlu $^{5} \cdot$ Ertuğrul Güçlü ${ }^{6}(1)$
}

Received: 26 December 2020 / Accepted: 17 February 2021 / Published online: 27 February 2021

(c) Royal Academy of Medicine in Ireland 2021

\begin{abstract}
Background Some biomarkers have been reported to be related to the prognosis of the coronavirus disease 2019 (COVID19). There are sparse data regarding the prognostic value of serum calprotectin in COVID-19 patients.

Aims This study aimed to investigate the relationship between serum calprotectin level and clinical severity of COVID-19 disease in hospitalized patients.

Methods This retrospective cross-sectional cohort study included 80 consecutive hospitalized patients with confirmed diagnosis of COVID-19. The study population was divided into two groups as patients hospitalized in the intensive care unit (ICU) and patients hospitalized but not in the ICU. The serum calprotectin levels, other laboratory, and clinical parameters were compared between groups.

Results The mean age of the patients was $66.5 \pm 15.7$ years. Of the patients, 42 were in the ICU and 38 were not. Serum calprotectin level and acute-phase reactants such as C-reactive protein, procalcitonin, ferritin, fibrinogen, and white blood cell were significantly higher in ICU patients than in non-ICU patients. ROC curve analysis identified that serum calprotectin level was a predictor for ICU requirement with an area under the curve of $0.641(p=0.031)$. Logistic regression analysis revealed that serum calprotectin was a significant determinant for whether or not patient required the ICU.

Conclusions These findings demonstrate that serum calprotectin level seems to be a useful biomarker that can predict the severity of COVID-19 disease. Serum calprotectin is a significant predictor of ICU requirement in patients with COVID-19.
\end{abstract}

Keywords Biomarkers $\cdot$ Calprotectin $\cdot$ Intensive care unit $\cdot$ Inflammation $\cdot$ SARS-CoV-2

\section{Introduction}

Severe acute respiratory syndrome coronavirus 2 (SARS$\mathrm{CoV}-2)$, classified as a novel coronavirus, causes coronavirus disease 2019 (COVID-19) in humans. This pandemic infection displays in a variety of ways, including asymptomatic, mild disease (such as fever, dry cough, weakness, muscle pain, diarrhea, nausea/vomiting, anosmia, and ageusia), and severe illness (such as pneumonia, acute respiratory distress syndrome (ARDS), disseminated intravascular coagulation, respiratory failure, shock, cytokine storm, multi-organ dysfunction, and death) $[1,2]$. Some laboratory parameters have been reported to be related to the diagnosis, clinical course, and prognosis of the disease [3-5]. For example, lymphopenia, neutrophilia, anemia, thrombocytopenia, and an increase in neutrophilto-lymphocyte ratio (NLR), C-reactive protein (CRP), procalcitonin, lactate dehydrogenase $(\mathrm{LDH})$, prothrombin time (PT), and D-dimer have been reported to be significant [3-5]. 
Calprotectin, a heterodimeric protein, is a member of the calcium-binding S100 protein family [6]. Calprotectin is located in the cytoplasm of neutrophils and monocytes, both of which play important roles in the inflammatory response in the human body [6]. It has been shown that serum calprotectin level increases secondary to inflammation in many inflammatory diseases [7-9]. It has also been reported that calprotectin can be used as a biomarker related to the activation, diagnosis, or prognosis of some diseases [7-12]. However, there are sparse data regarding the relationship between serum calprotectin and COVID-19 disease [13-16]. Therefore, this study aimed to investigate the relationship between serum calprotectin level and clinical severity of COVID-19 disease in hospitalized patients.

\section{Methods}

\section{Design and patients}

Consecutive hospitalized patients diagnosed with COVID19 disease between November 1, 2020 and December 10, 2020 were included in this study, which was designed as a retrospective cross-sectional cohort study in a tertiary university hospital. COVID-19 diagnosis was made using the reverse transcription polymerase chain reaction test via nasopharyngeal and oropharyngeal swabs. Patients were excluded from this study if they were under the age of 18 years; pregnant; diagnosed with malignancy; had sepsis, septic shock, or proven bacterial infection; were using immunosuppressive drugs; or had chronic inflammatory disease or autoimmune disease.

Within the scope of this study, the demographic and clinical data of the patients were recorded from patient follow-up files. The study population was evaluated in two groups, as hospitalized in the intensive care unit (ICU) and hospitalized non-ICU. Criteria for ICU were respiratory failure, ARDS, or multiple organ failure. Demographic/ clinical data, laboratory parameters, and serum calprotectin were compared between groups.

The study protocol was approved by the local University Ethics Committee (No. 71522473/050.01.04/471).

\section{Laboratory examinations}

Venous blood samples were drawn from all included patients at the time of hospitalized in the ICU or nonICU. EDTA tubes for complete blood count (CBC), tubes containing 3.8\% Na-citrate for coagulation parameters, and anticoagulant-free biochemistry tubes were used for serum tests. CBC samples were studied immediately after the samples arrived at the biochemistry laboratory. Regarding the other tests, once the coagulation process of the samples received in tubes without anticoagulants was completed, the venous blood samples were centrifuged at $1500 \times g$ for $10 \mathrm{~min}$. The samples were closely monitored to determine whether any became hemolyzed or lipemic. Biochemistry parameters were studied from the serum. After the diagnosis of COVID-19 was made, sera obtained after centrifugation for the serum calprotectin study were stored at $-80 \mathrm{C}$ until further use. Prior to analysis for calprotectin, all samples were carefully brought to room temperature (15-18 C) and homogenized before use.

Serum albumin, $\mathrm{LDH}$, creatinine, calcium, alanine aminotransferase (ALT), aspartate aminotransferase (AST), and creatine kinase levels were measured by the spectrophotometric method, and CRP was measured by the immunoturbidimetric method via an Olympus AU5800 (Beckman Coulter, Inc. Brea, CA92821 USA) autoanalyzer. Ferritin level was measured with the chemiluminescence method in an ABBOTT ARCHITECT I 2000 SR device (Abbott Laboratories Abbott Park IL, 60064, USA); CBC parameters were measured using a CELL-DYN 3700 CD-3700SL device with laser measurement and LED Flow Cell method (Abbott Diagnostics Division, Abbott Laboratories Abbott Park IL, 60064, USA). PT and fibrinogen levels were measured by an optical method, D-dimer level was measured by a latex agglutination method in a Diagon CoagXL device (Budapest, Hungary), and procalcitonin level was measured by the immunoassay method using a Roche Cobas e 411 (Hitachi, 6544-01 Tokyo Japan). Serum calprotectin levels were measured by the sandwich ELISA method (Elabsience, Bioassay Technology Laboratory, Shanghai, China) (calprotectin $\mathrm{ng} / \mathrm{mL}$ ). In the precision study performed by the manufacturer, the within-run and between-run $\mathrm{CV} \%$ of the kits were $<10 \%$.

\section{Statistical analysis}

Data were analyzed using SPSS 20.0 for Windows software (SPSS Inc., Chicago, IL, USA). Descriptive analyses of the variables were expressed as mean $\pm \mathrm{SD}$ in normal distributions, and parameters with abnormal distribution were expressed as medians of the 25th-75th percentile. Categorical data were expressed as proportions. The Kolmogorov-Smirnov test was used to control the data distribution. The chi-square and the Student's $t$ test were used for categorical and continuous variables, respectively. For continuous variables, differences between the two groups were evaluated using the Student's $t$ test when data were normally distributed and the Mann-Whitney $U$ test when the assumption of normality was not met. Receiver operating curve (ROC) analysis was used to calculate for serum 
Table 1 Demographic and clinical characteristics of inpatients with COVID-19

\begin{tabular}{llll}
\hline Parameters & $\begin{array}{l}\text { Patients in } \\
\text { ICU }(n=38)\end{array}$ & $\begin{array}{l}\text { Patients in } \\
\text { non-ICU } \\
(n=42)\end{array}$ & $P$ value \\
\hline Age (years) & $70.8 \pm 12.8$ & $62.5 \pm 17.2$ & 0.034 \\
Age $\geq 65$ years & 29 & 20 & 0.008 \\
Gender (male/female) & $24 / 14$ & $19 / 23$ & 0.083 \\
Diabetes mellitus & 9 & 17 & 0.086 \\
Hypertension & 19 & 23 & 0.420 \\
Coronary artery disease & 13 & 7 & 0.060 \\
Renal failure & 5 & 3 & 0.301 \\
Chronic respiratory disease & 4 & 2 & 0.291 \\
\hline
\end{tabular}

ICU intensive care unit

calprotectin levels the required cut-off values to distinguish ICU patients with maximum sensitivity and specificity. Binary logistic regression analysis was performed to determine predictive value of calprotectin for ICU patients. $P$ values $<0.05$ were considered statistically significant.

\section{Results}

Of the 80 consecutive COVID-19 patients included in the study, 42 were followed in the ICU and 38 in the non-ICU. Forty-three of the patients were male, 37 were female, and the mean age was $66.5 \pm 15.7$ years. Comorbid chronic diseases and demographic characteristics of the study population are shown in Table 1. The average age of the ICU patients was significantly higher than those in the non-ICU, and most patients in the ICU were geriatric (age $\geq 65$ years). Serum calprotectin level and acutephase reactants such as CRP, procalcitonin, ferritin, fibrinogen, and white blood cells (WBCs) were significantly higher in ICU patients than in non-ICU patients $(p=0.031, p<0.001$, $p<0.001, p<0.001, p=0.009, p=0.001$ respectively) (Table 2). Serum calprotectin levels of COVID-19 patients in the ICU and non-ICU are shown in Fig. $1(p=0.031)$. Mechanical ventilation requirement and mortality rate of 42 patients followed in ICU were $61.9 \%$ (26 patients) and $57.1 \%$ (24 patients) respectively.

An ROC curve was used to verify the optimum cut-off point for serum calprotectin level for predicting whether or not a patient required the ICU. The area under the ROC curve (AUC) was 0.641 (95\% CI: $0.518-0.763, p=0.031)$ for calprotectin (Fig. 2). The recommended cut-off value for calprotectin was 45.65 with a sensitivity of $50 \%$ and a specificity of $73.2 \%$. Binary logistic regression analysis was performed to determine the ability of the serum calprotectin level to predict the patient required the ICU. The analysis revealed that serum calprotectin was a significant determinant for patients requiring the ICU (OR $1.029,95 \%$ CI $1.004-1.005, p=0.024)$.
Table 2 Patients' serum calprotectin and other laboratory parameters

\begin{tabular}{|c|c|c|c|}
\hline Variable & $\begin{array}{l}\text { Patients in ICU } \\
(n=38)\end{array}$ & $\begin{array}{l}\text { Patients in non-ICU } \\
(n=42)\end{array}$ & $P$ value \\
\hline $\begin{array}{l}\text { White blood } \\
\text { cells }(\mathrm{K} / \mu \mathrm{L})\end{array}$ & $8.4(6-11.3)$ & $5.1(4.2-8)$ & 0.001 \\
\hline $\begin{array}{l}\text { Neutrophil (K/ } \\
\mu \mathrm{L})\end{array}$ & $6.3(4.4-9.2)$ & $3.5(2.3-4.9)$ & $<0.001$ \\
\hline $\begin{array}{l}\text { Lymphocytes } \\
(\mathrm{K} / \mu \mathrm{L})\end{array}$ & $0.7(0.5-1.2)$ & $1.3(0.9-1.9)$ & $<0.001$ \\
\hline $\begin{array}{l}\text { Hemoglobin } \\
(\mathrm{g} / \mathrm{dL})\end{array}$ & $12.2 \pm 1.7$ & $12.2 \pm 1.5$ & 0.969 \\
\hline $\begin{array}{l}\text { Platelets }(\mathrm{K} / \\
\mu \mathrm{L})\end{array}$ & $187(145-241)$ & $190(133-240)$ & 0.278 \\
\hline $\begin{array}{l}\text { D-Dimer } \\
(\mu \mathrm{gFEU} / \mathrm{L})\end{array}$ & $\begin{array}{l}1360(789- \\
2082)\end{array}$ & $516(278-895)$ & $<0.001$ \\
\hline $\begin{array}{c}\text { Fibrinogen } \\
(\mathrm{mg} / \mathrm{dL})\end{array}$ & $405(346-472)$ & $320(294-380)$ & 0.009 \\
\hline $\begin{array}{l}\text { Prothrombin } \\
\text { time (s) }\end{array}$ & $\begin{array}{l}13.3(12.3- \\
14.5)\end{array}$ & $12(11-13.7)$ & 0.003 \\
\hline NLR & $7(4.9-11.3)$ & $2.7(1.6-4)$ & $<0.001$ \\
\hline $\begin{array}{l}\text { Calprotectin } \\
(\mathrm{ng} / \mathrm{mL})\end{array}$ & $\begin{array}{l}44.8(34.5- \\
61.5)\end{array}$ & $37.9(30.3-46.2)$ & 0.031 \\
\hline Ferritin $(\mu \mathrm{cg} / \mathrm{L})$ & $\begin{array}{c}617(416- \\
1469)\end{array}$ & $268(132-623)$ & $<0.001$ \\
\hline $\begin{array}{l}\text { Creatinine (mg/ } \\
\text { dL) }\end{array}$ & $0.9(0.8-1.1)$ & $0.73(0.6-0.97)$ & 0.040 \\
\hline AST (U/L) & $44(28-56)$ & $31(22.7-41)$ & 0.008 \\
\hline ALT (U/L) & $26(15-36.2)$ & $22.5(15-37.7)$ & 0.828 \\
\hline $\begin{array}{l}\text { Albumin (gr/ } \\
\mathrm{dL})\end{array}$ & $2.9 \pm 0.4$ & $3.4 \pm 0.4$ & $<0.001$ \\
\hline CRP (mg/L) & $120(73-178)$ & $26.5(7.8-90.2)$ & $<0.001$ \\
\hline $\begin{array}{l}\text { Procalcitonin } \\
\text { (ng/ml) }\end{array}$ & $\begin{array}{l}0.26(0.09- \\
1.03)\end{array}$ & $0.08(0.04-0.20)$ & $<0.001$ \\
\hline LDH (U/L) & $431(367-536)$ & $259(195-329)$ & $<0.001$ \\
\hline
\end{tabular}

Data are presented as mean \pm standard deviation for continuous variables with normal distribution, median and 25th and 75th percentiles (P25-P75) for variables with non-normal distribution

$I C U$ intensive care unit, NLR neutrophil-lymphocyte ratio, AST aspartate aminotransferase, ALT alanine aminotransferase, CRP C-reactive protein, $L D H$ lactate dehydrogenase

\section{Discussion}

The current study revealed that serum calprotectin levels of COVID-19 patients in the ICU are significantly higher than those of COVID-19 patients in the non-ICU. In addition, the present study showed that serum calprotectin value for hospitalized COVID-19 patients is a significant predictor for requiring the ICU. Serum calprotectin level appears to be a useful biomarker as an indicator of COVID-19 disease severity. Calprotectin may be useful for distinguishing moderate or severe COVID-19 patients.

COVID-19 disease can cause several different clinical situations. Conditions such as pneumonia, ARDS, 


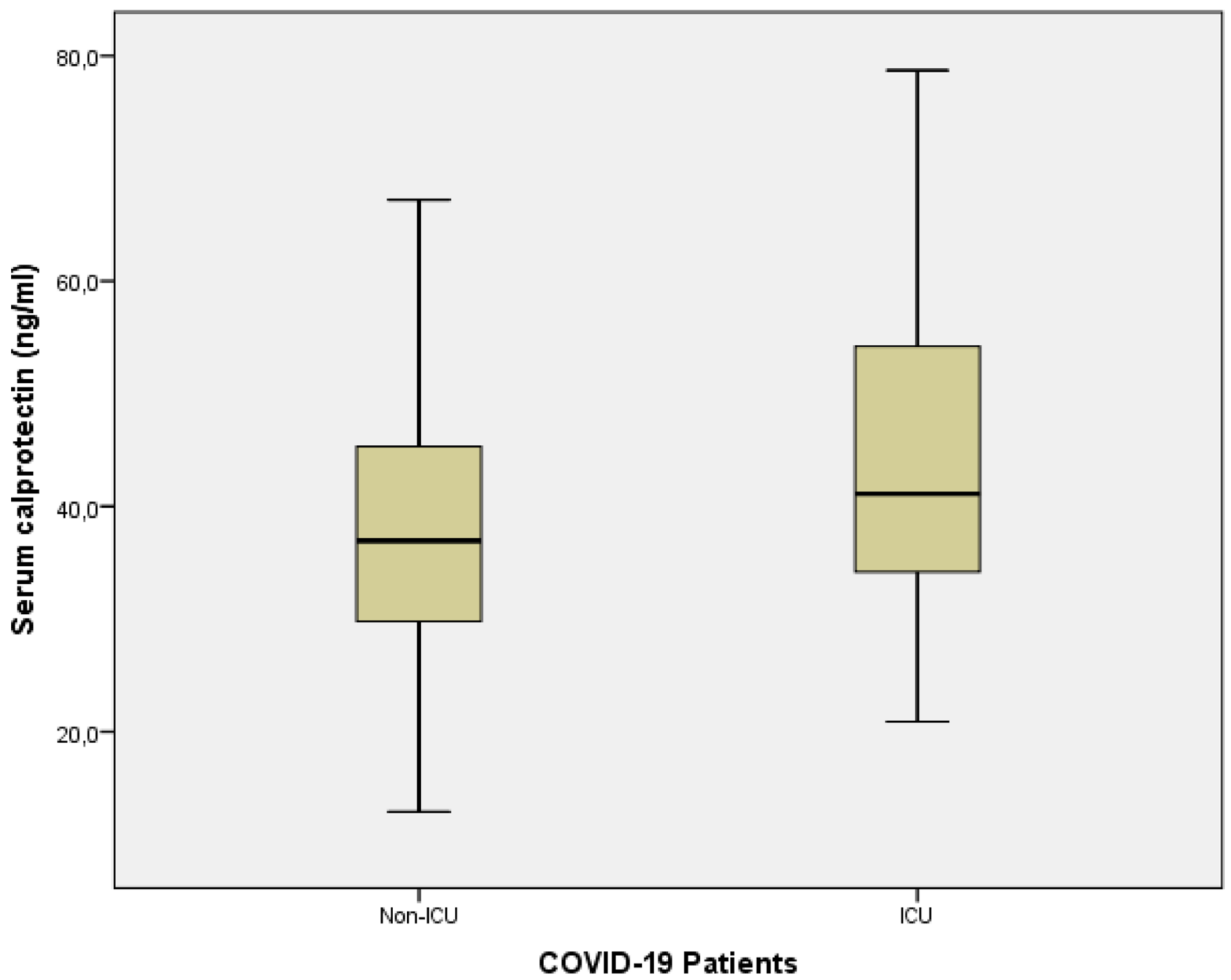

Fig. 1 Serum calprotectin levels of COVID-19 patients in intensive care unit (ICU) and non-ICU ( $p=0.031$, assessed by Mann-Whitney $U$ test)

disseminated intravascular coagulation, respiratory failure, shock, cytokine storm, and multi-organ dysfunction can be seen in severe COVID-19 disease $[1,2,17]$. In these clinical situations, patients generally require follow-up and treatment in the ICU $[17,18]$. Severe disease also increases morbidity and mortality rates $[17,18]$. Studies have reported that some biomarkers can distinguish mild/moderate and severe disease in COVID-19 patients at an early stage [4-6, 19]. In a metaanalysis, Henry et al. reported that WBC count, lymphocyte count, platelet count, IL-6, and serum ferritin are markers for progression to critical illness [19].

In another systematic review and meta-analysis, Ghahramani et al. revealed that compared with a non-severe group, a group of patients with severe COVID-19 disease had significant decreases in lymphocytes, monocytes, eosinophils, hemoglobin, platelets, and albumin and significant increases in neutrophils, CRP, procalcitonin, $\mathrm{LDH}$, fibrinogen, PT, AST, D-dimer, and NLR [5]. In the current study, WBC, neutrophils, lymphocytes, D-dimer, fibrinogen, PT, NLR, ferritin, AST, albumin, CRP, procalcitonin, and LDH values were significantly different in ICU patients. The results of our study are consistent with these two prior meta-analyses [5, 19].

Calprotectin is a protein that is especially secreted by neutrophils secondary to inflammation. It has recently been reported that calprotectin can be used as a biomarker of inflammation for assessing the activity of some inflammatory disorders [7-12]. However, there are few published studies regarding the relationship between serum calprotectin and COVID-19 severity. In their study including 121 COVID-19 patients (40 ICU, 81 non-ICU), Chen et al. reported that ICU-admission COVID-19 patients had significantly elevated levels of serum calprotectin (S100A8/A9) compared with nonICU patients, and that patients with fatal outcomes had significantly more calprotectin than those who lived [20]. In addition, according to that study, a significant elevation 
Fig. 2 Receiver-operating characteristic (ROC) analysis of calprotectin as indicator to predict COVID19 patients for intensive care unit $(\mathrm{AUC}=0.641 ; 95 \% \mathrm{CI}$, $0.518-0.763)$

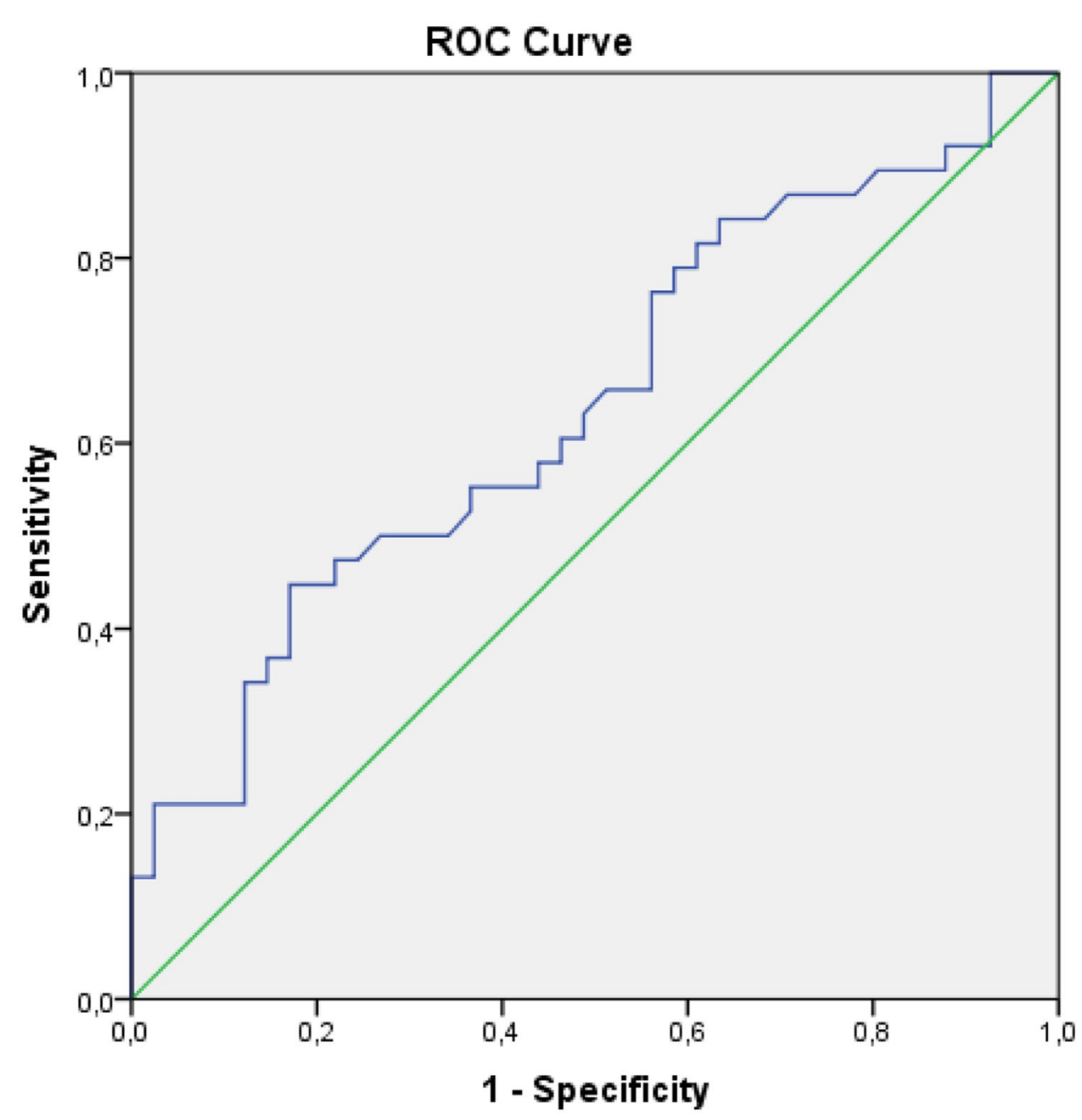

of serum calprotectin was associated with high mortality in COVID-19 patients [20].

In their study with 94 COVID-19 patients, Shi et al. reported that the serum calprotectin levels of patients requiring mechanical ventilation were higher than those who did not need intubation [14]. In another study of 66 COVID-19 patients, Romualdo et al. revealed that the serum calprotectin levels of patients who died were higher than of those who lived [16].

The present study has some limitations. First, there was relatively small number of patients, and the patients were from a single center. A multi-center study involving more patients and countries would be more beneficial. Second, in this study, serum calprotectin was measured only once at the time of admission to the inpatient service or ICU. Patient follow-up could be better with daily or every other day serum calprotectin measurement. Finally, serum calprotectin measurement is not routinely performed in most hospitals, and this assay may be relatively expensive compared with other acute phase reactants.
Similar to the results of the very recent studies reported above, in the present study, serum calprotectin was significantly higher in ICU patients with severe disease than in non-ICU patients with moderate disease. In addition, calprotectin served as a significant predictor for ICU requirement in COVID-19 patients. In conclusion, these findings suggest that serum calprotectin may be a novel biomarker in the assessment of poor outcome in COVID-19 patients.

Author contribution Conceptualization: TK, SY, AN. Methodology: TK, IY, HK. Formal analysis and investigation: EÇ, MRŞ, IY. Writing-original draft preparation: TK, SY, AN. Writing-review and editing: TK, MK, EG. Resources: IYY, MK, EÇ. Supervision: MRŞ, MK, EG.

\section{Declarations}

Ethical approval The study protocol was approved by the Ethics Committee of Sakarya University Faculty of Medicine, Sakarya, Turkey (No: 71522473 / 050.01 .04 / 471). 
Conflict of interest The authors declare that they have no conflict of interest.

\section{References}

1. Huang R, Zhuid L, Xue L et al (2020) Clinical findings of patients with coronavirus disease 2019 in Jiangsu Province, China: a retrospective, multi-center study. PLoS Negl Trop Dis 14:1-14. https://doi.org/10.1371/journal.pntd.0008280

2. Kouhsari E, Azizian K, Sholeh M et al (2020) Clinical, epidemiological, laboratory, and radiological characteristics of novel Coronavirus (2019-nCoV) in retrospective studies: a systemic review and meta-analysis. Indian J Med Microbiol. https://doi.org/10.1016/j.ijmmb.2020.10.004

3. Pourbagheri-Sigaroodi A, Bashash D, Fateh F et al (2020) Laboratory findings in COVID-19 diagnosis and prognosis. Clin Chim Acta 510:475-482. https://doi.org/10.1016/j. cca.2020.08.019

4. Ponti G, Maccaferri M, Ruini C et al (2020) Biomarkers associated with COVID-19 disease progression Crit Rev Clin Lab Sci 1-11. https://doi.org/10.1080/10408363.2020.1770685

5. Ghahramani S, Tabrizi R, Lankarani KB et al (2020) Laboratory features of severe vs. non-severe COVID-19 patients in Asian populations: a systematic review and meta-analysis. Eur J Med Res 25:1-10. https://doi.org/10.1186/s40001-020-00432-3

6. Wang S, Song R, Wang Z et al (2018) S100A8/A9 in inflammation. Front Immunol 11(9):1298. https://doi.org/10.3389/fimmu. 2018.01298

7. Romand X, Bernardy C, Nguyen MVC et al (2019) Systemic calprotectin and chronic inflammatory rheumatic diseases. Jt Bone Spine 86:691-698. https://doi.org/10.1016/j.jbspin.2019.01.003

8. Wirtz TH, Buendgens L, Weiskirchen R et al (2020) Association of serum calprotectin concentrations with mortality in critically ill and septic patients. Diagnostics 10:990. https://doi.org/10.3390/ diagnostics10110990

9. Kunutsor SK, Flores-Guerrero JL, Kieneker LM et al (2018) Plasma calprotectin and risk of cardiovascular disease: findings from the PREVEND prospective cohort study. Atherosclerosis 275:205-213. https://doi.org/10.1016/j.atheroscle rosis. 2018.06.817

10. Wang Q, Chen W, Lin J (2019) The role of calprotectin in rheumatoid arthritis. J Transl Int Med 7(4):126-131. https://doi. org/10.2478/jtim-2019-0026
11. Yurtsever Kum N, Kum RO, Candar T et al (2020) Elevated serum calprotectin as an inflammatory marker in obstructive sleep apnea. Cranio 21:1-7. https://doi.org/10.1080/08869634.2020.1839721

12. Candar T, Baklaci D, Kuzucu I, Kayabasi S (2020) A proinflammatory marker in chronic rhinosinusitis: serum calprotectin. Acta Biochim Pol 31;67(3):367-371. https://doi. org/10.18388/abp.2020_5204

13. Silvin A, Chapuis N, Dunsmore G, Goubet AG et al (2020) Elevated calprotectin and abnormal myeloid cell subsets discriminate severe from mild COVID-19. Cell 182:1401-1418. e18. https://doi.org/10.1016/j.cell.2020.08.002

14. Shi H, Zuo Y, Yalavarthi S et al (2020) Neutrophil calprotectin identifies severe pulmonary disease in COVID-19. J Leukoc Biol 1-20.https://doi.org/10.1002/JLB.3COVCRA0720-359R

15. Bauer W, Diehl-Wiesenecker E, Ulke J et al (2020) Outcome prediction by serum calprotectin in patients with COVID-19 in the emergency department. J Infect. https://doi.org/10.1016/j. jinf.2020.11.016

16. García L, de Guadiana Romualdo MDR, Mulero MHO et al (2020) Circulating levels of GDF-15 and calprotectin for prediction of in-hospital mortality in COVID-19 patients: a case series. J Infect S0163-4453(20):30543. https://doi.org/10.1016/j. jinf.2020.08.010

17. Grasselli G, Zangrillo A, Zanella A et al (2020) Baseline characteristics and outcomes of 1591 patients infected with SARS-CoV-2 admitted to ICUs of the lombardy region. Italy JAMA 323:1574. https://doi.org/10.1001/jama.2020.5394

18. Cattelan AM, Di Meco E, Trevenzoli M et al (2020) Clinical characteristics and laboratory biomarkers changes in COVID19 patients requiring or not intensive or sub-intensive care: a comparative study. BMC Infect Dis 20:934. https://doi. org/10.1186/s12879-020-05647-7

19. Henry BM, de Oliveira MHS, Benoit S et al (2020) Hematologic, biochemical and immune biomarker abnormalities associated with severe illness and mortality in coronavirus disease 2019 (COVID19): a meta-analysis. Clin Chem Lab Med 58:1021-1028. https:// doi.org/10.1515/cclm-2020-0369

20. Chen L, Long X, Xu Q et al (2020) Elevated serum levels of S100A8/A9 and HMGB1 at hospital admission are correlated with inferior clinical outcomes in COVID-19 patients. Cell Mol Immunol 17:992-994. https://doi.org/10.1038/s41423-020-0492-x 